\title{
How much do we know about the endangered Atlantic Forest? Reviewing nearly 70 years of information on tree community surveys
}

\author{
Renato A. F. de Lima ${ }^{1}$ - Danilo P. Mori ${ }^{1}$ Gregory Pitta ${ }^{1}$ • \\ Melina O. Melito ${ }^{1}$ - Carolina Bello ${ }^{2}$ Luiz F. Magnago ${ }^{3}$. \\ Victor P. Zwiener ${ }^{4}$ - Daniel D. Saraiva ${ }^{5}$ Márcia C. M. Marques ${ }^{4}$. \\ Alexandre A. de Oliveira ${ }^{1}$ - Paulo I. Prado ${ }^{1}$
}

Received: 14 April 2015/Revised: 9 June 2015/Accepted: 19 June 2015/

Published online: 1 July 2015

(C) Springer Science+Business Media Dordrecht 2015

\begin{abstract}
The structure of the Atlantic Forest (AF) has been studied for almost 70 years. However, the related existing knowledge is spread over hundreds of documents, many of them unpublished and/or difficult to access. Synthesis initiatives are available, but they are restricted to only a few parts or types of the AF or are focused on species occurrence. Here, we conducted an extensive review to compile quantitative tree community surveys on all types of the AF until 2013 and to study where and how these surveys were conducted. We found 1157 relevant references, containing 2441 forest surveys published since 1945. These surveys corresponded to 2.24 million trees and 1817 ha of forests sampled. This total sampled area represents only $0.01 \%$ of the AF remnants, showing how limited our knowledge is on AF structure. For Paraguay and the Brazilian states of Bahia and Mato Grosso do Sul this proportion was much smaller. The same was true for evergreen rainforests, Brejos de altitude and deciduous forests and most probably for the rare cloud, swamp, Caxetal and Mussununga forests for which no accurate remnant estimates were
\end{abstract}

Communicated by Jefferson Prado, Pedro V. Eisenlohr and Ary T. de Oliveira-Filho.

Electronic supplementary material The online version of this article (doi:10.1007/s10531-015-0953-1) contains supplementary material, which is available to authorized users.

Renato A. F. de Lima

raflima@usp.br

1 Departamento de Ecologia, Instituto de Biociências, Universidade de São Paulo (USP), São Paulo, SP 05508-090, Brazil

2 Departamento de Ecologia, Instituto de Biociências, Universidade Estadual Paulista (UNESP), Rio Claro, SP 13506-900, Brazil

3 Departamento de Biologia, Setor de Ecologia e Conservação, Universidade Federal de Lavras (UFLA), Lavras, MG 37200-000, Brazil

4 Departamento de Botânica, Setor de Ciências Biológicas, Universidade Federal do Paraná (UFPR), PO Box 19031, Curitiba, PR 81531-980, Brazil

5 Programa de Pós-Graduação em Botânica, Instituto de Biociências, Universidade Federal do Rio Grande do Sul (UFRGS), Porto Alegre, RS 91501-970, Brazil 
found. Since the 1980s, the amount of AF area sampled each year has increased continuously, but approximately 100 years will be necessary to sample at least $1 \%$ of the AF. Thus, we urgently need an enormous amount of high-quality quantitative data to overcome our limited knowledge of the AF and to support conservation programs aiming to safeguard this threatened biodiversity hotspot.

Keywords Forest inventories · Mata Atlântica · Phytosociology · Sampling methods · Tropical forest

\section{Introduction}

Forest fragmentation and degradation are widespread processes that inevitably lead to biodiversity loss, climate change and ecosystem service depletion (MEA 2005; Magnago et al. 2014). In the Neotropics, the Atlantic Forest (AF) is a good example of how these processes can alter natural ecosystems. Subject to degradation for more than 500 years, there is currently less than $15 \%$ of its original extent, and its remnants are mostly comprised of small ( $<50 \mathrm{ha}$ ), isolated and disturbed fragments (Ribeiro et al. 2009). Despite being the fourth hottest biodiversity hotspot with 1-8\% of the world's species and one of the highest rates of endemism of plants, insects, mammals and birds on the planet (Goerck 1997; Thomas et al. 1998; Myers et al. 2000), the AF continues to be deforested at a rate of 20,000 ha per year (SOS Mata Atlântica 2014). The future of the AF will depend on wellplanned, large-scale conservation strategies that must be founded on quality information about its remnants to support informed decision-making processes (Thiollay 2002; Kim and Byrne 2006), including the creation of new protected areas, the planning of restoration projects and the management of natural resources.

Quantitative forest surveys, also referred to as forest inventories, are useful sources of information in planning the conservation of tropical forests (ter Steege 1998). Because they are applied using sampling protocols they provide more information than the occurrence of species, which is used to study geographical distributions (Soberón and Peterson 2004). Quantitative surveys also provide measures of species diversity, forest structure and more recently carbon stocks, which are often used as biodiversity indicators (Corona et al. 2011). Because they generally provide counts of individuals of each species occurring in a given site, these surveys can be used to assess the structure and viability of populations of endangered species (Morris and Doak 2002). Additionally, if such surveys are conducted periodically and/or over large areas, then we can begin to understand the main forces shaping the structure and diversity of tropical forests across time and space.

The first quantitative forest surveys on the AF were published in 1945 by Davis (1945) and Veloso (1945). These studies were primarily focused on the transmission of yellow fever and included surveys of the hosts and vectors of the disease (Martins 1989). Subsequent studies by Veloso were more interested in the AF itself and included the first attempts at defining species associations and estimating tree species diversity (Veloso 1946; Veloso and Klein 1957, 1968). Until the end of the 1970s, few other studies were published, most attempting to assess AF timber potential (Cain et al. 1956; Campos and Heinsdijk 1970; Tavares et al. 1971). After the publication of a classic study by Martins (1979), quantitative surveys became a common tool for describing Brazilian forests. Generally applied using phytosociological descriptions of the dominant forest stratum 
(Freitas and Magalhães 2012), these studies varied greatly in their aims and forest types studied (Giehl and Budke 2011). They became a well-established research program until the end of the last century and in the last 10 years several large inventory projects were established (Jesus and Rolim 2005; Rodrigues 2005; Scolforo et al. 2008; Rode et al. 2011; Joly et al. 2012; Vibrans et al. 2013).

Today, there is a huge amount of information on the structure and composition of the AF that is spread over hundreds of documents, with many of them being difficult to access. These documents have been subject to previous synthesis (Oliveira-Filho and Fontes 2000; Scudeller and Martins 2003; Hargreaves 2008). Using quantitative surveys published until 2005, Caiafa and Martins (2007) summarized the available information on the structure of the evergreen AF. However, past initiatives generally were restricted to a given AF type, region and/or were focused on the phytogeography of the AF. Almost a decade later, we present an extensive literature review to summarize our current knowledge on the structure of the AF, including all of its forest types and regions. Our aims include the following: (i) to present the state of art of quantitative forest surveys in the AF, (ii) to assess how the information contained in these surveys varies across time, space and among different types of the AF, and (iii) to summarize the different methodologies used to obtain this information. Finally we discuss the potential and limitations of using the available information on AF structure as a guideline toward planning the conservation of this endangered biodiversity hotspot.

\section{Methods}

\section{The Atlantic Forest}

Our study was restricted to the AF, a Neotropical domain that ranges from approximately $5^{\circ}-33^{\circ}$ in latitude $\mathrm{S}$ and $35^{\circ}-57^{\circ}$ in longitude $\mathrm{W}$, extending across the eastern coast of Brazil and also reaching continental areas in northeastern Argentina and southeastern Paraguay (Fig. 1). These areas are extremely heterogeneous in terms of climate, soil and altitude (Veloso 1992). Consequently, the AF comprises several types of forests, including evergreen, semi-deciduous, deciduous, mixed temperate (locally known as Araucaria forests), white-sand (Restingas and Mussunungas), open canopy (Brejos de altitude), alluvial, cloud and swamp forests, all of which vary greatly in their species composition (Oliveira-Filho and Fontes 2000). We have not considered forests of the Cerrado domain, such as savanna forests (Cerradão) and gallery forests, even if they were within the limits of the AF domain. However, we included all surveys of the AF types listed above even if they were conducted in forest fragments outside of the core limits of the AF domain.

\section{Systematic review and data extraction}

The review protocol that was used to identify existing quantitative tree community surveys was adapted from Pullin and Stewart (2006; full details are give in electronic supplementary material 1). We searched for potential studies in the following sources: (i) online academic databases (e.g., ISI Web of Knowledge) (ii) digital libraries of state and federal universities, (iii) references cited in local literature, and (iv) email contacts with local experts (Tables S1 and S2). The terms used to search the online databases were "forest", "tree", "structure", "phytosociology", and "Atlantic Forest", which were combined in 
different ways using Boolean operators. Searches were conducted in English, Portuguese and Spanish. We considered all types of documents as well as grey literature (e.g., theses, scientific conferences, and technical reports). The search in sources i and ii was conducted in October 2013 but many studies from source iii were added after that. We received answers from experts until April 2014. Although we considered studies published until 2013, some important ongoing studies and articles in press that were suggested by experts were included as well.

After the removal of duplicates and spurious hits, we performed a title and abstract inspection to exclude studies that were purely qualitative (floristic studies), that considered only non-tree species or that were conducted exclusively in mangroves, shrubby physiognomies of Restinga, or restored and managed forests (locally known as Cabrucas or Faxinais). Following this, we conducted a full-text inspection of the remaining studies to guarantee the inclusion of studies with clearly defined sampling methods that presented quantitative results such as species counts, abundance distributions or biomass estimates. We performed no filtering based on sampling methods, forest successional stage, effort, type (e.g., species counts, tree density and/or biomass estimates) or quality (e.g., taxonomic resolution) of the presented results. Due to a bias in the search terms, studies including only initial tree development (natural regeneration studies) were underestimated in the review and thus were not included in the analysis. Finally, whenever the same data or different censuses at the same sites were presented in two or more studies, we considered only the most recent study/census, the census that was conducted prior to any major disturbance or the census the was published in peer-reviewed journals.

For each survey, we extracted location (country, state, county and locality), geographic coordinates, forest type, sampling design (random, systematic or aggregated), sampling method (plots, point-centered quarters (PCQ) or transects, and sample unit dimensions), size cutoff criteria (dbh or height), sample size (number of individuals and sampled area), year of publication and affiliation of first author. We also recorded the conservation category of the land surveyed (e.g., private, conservation unit). We defined transects as line transects or elongated plots of less than one meter in width. Whenever geographic coordinates were not given, we used the coordinates at the center of the corresponding county. Values of cutoff criteria that were higher $(>)$ and higher or equal $(\geq)$ to a certain size were assumed as equivalents. In addition, we converted stem perimeter into diameter prior to analysis. Forest type classification followed Veloso (1992) and was made based on descriptions given by the authors of each study. Whenever such a classification was not given, the species list provided was carefully inspected to assign a forest type based on our experience. If one study presented two or more surveys, information was extracted separately for each survey.

\section{Data management and analysis}

To describe the contributions of region and AF type, we first calculated the frequency and total effort of surveys for each of them. We then calculated the proportion of AF area sampled by these surveys in each state or forest type. The remaining AF area in Brazil was obtained from the last available report on AF remnants (SOS Mata Atlântica 2014). For Argentina and Paraguay, this information was extracted from a study by Plací and Di Bitetti (2006). These two countries were treated at the same level as Brazilian states to simplify data presentation. The remaining AF area of each forest type was obtained from a study by Cruz and Vicens (2007). Unfortunately, 186 surveys did not report total area sampled, mainly those using the PCQ method. For these surveys, we estimated sampled 
area based on the mean values of tree density of all other surveys using the same cutoff criteria (Area $=N / D A$, where $N$ is the total number of individuals, and $D A$ is the mean tree density per hectare). These estimates are certainly imprecise, but they allowed us to have at least an approximate sampled area for all surveys.

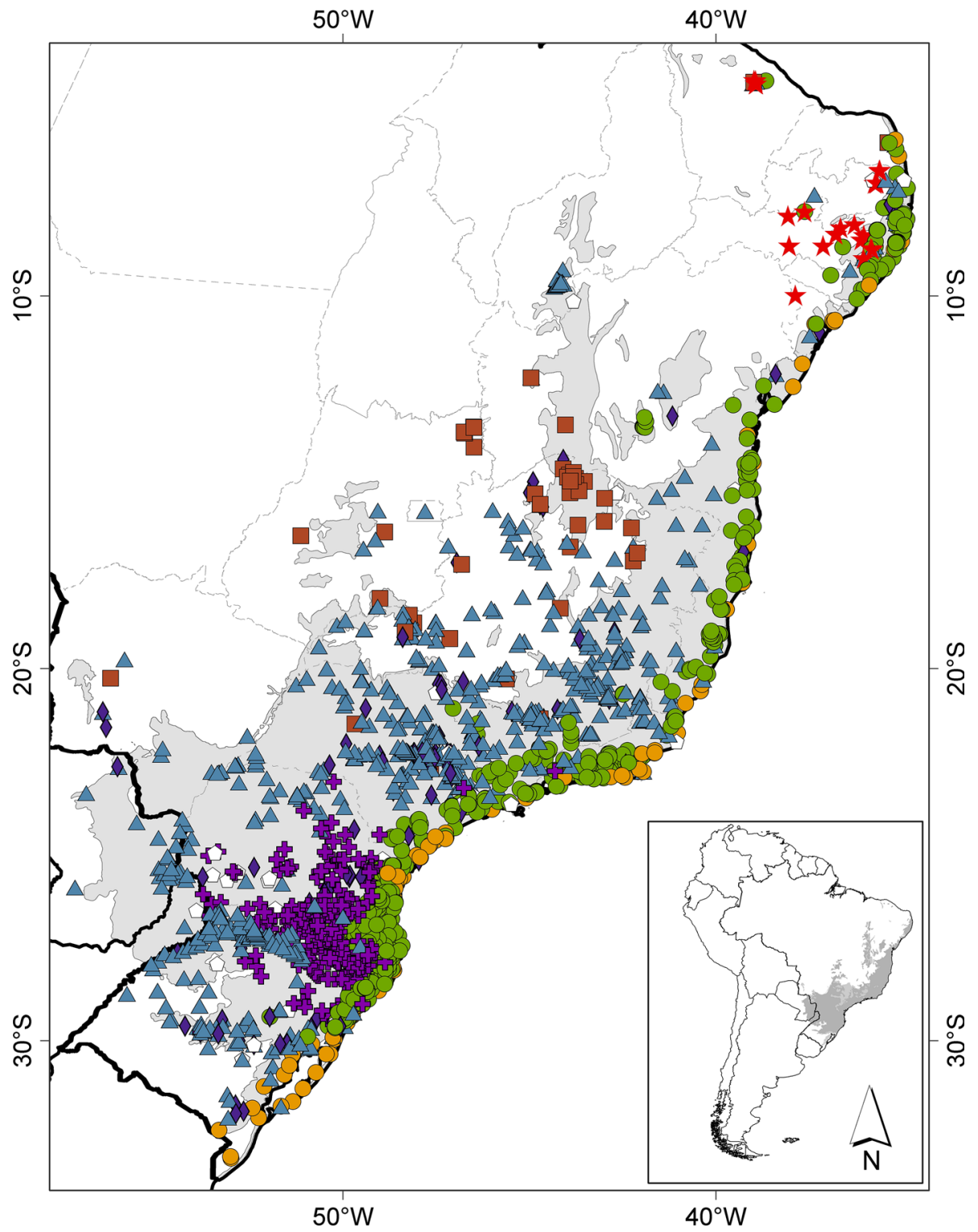

Fig. 1 The Atlantic Forest and the location of all surveys found in this study. The gray shadow delimits the Atlantic Forest, while political limits are given by bold black (countries) and dashed lines (Brazilian states). The symbols represent the different Atlantic Forest types given in Table 3 including semi-deciduous (blue triangles), evergreen (white circles), Araucaria (dark-grey crosses), deciduous (white squares), ecotones (grey pentagons), Restinga (dark-grey circles), alluvial (white diamonds) and open canopy forests (i.e. Brejos de Altitude, white stars). (Color figure online) 
To present the overall results of the contributions of each region, forest type, research institution and conservation category to the available knowledge of the AF, we ranked each of these groups while taking into account four measures of information. Here, we use the general term 'knowledge' as a combination of these four measures, which include: number of studies (S), number of inventories or surveys conducted by these studies (I), number of individuals (N) and total area sampled (A). However, because each of these measures of information have different impacts on the amount of knowledge that is available on the AF, we calculated a weighted rank that is actually a weighted mean of the ranks calculated separately for each of these measures of information:

$$
\text { Weighted rank }=\left(0.5 \operatorname{rank}_{\mathrm{S}}+0.75 \operatorname{rank}_{\mathrm{I}}+\operatorname{rank}_{\mathrm{N}}+0.75 \operatorname{rank}_{\mathrm{A}}\right) / 4,
$$

where $\operatorname{rank}_{\mathrm{S}}, \operatorname{rank}_{\mathrm{I}}, \operatorname{rank}_{\mathrm{N}}$ and $\operatorname{rank}_{\mathrm{A}}$ represent the ordered position of a given region, AF type, institution or conservation category with respect to each measure of information (S, I, $\mathrm{N}$ and $\mathrm{A}$ ). Here the lower the value, the better the rank. That is, groups with smaller ranks are those having higher values of S, I, N and A, and they are therefore concentrating larger amounts of the available knowledge. Weights were defined arbitrarily according to our opinion in which measure reflects more accurately how much we know about a given forest. The number of individuals surveyed $(\mathrm{N})$ is to us the most critical measure of information of a given tree community (weight $=1$ ) because it defines more directly the amount of information available to assess its composition, structure and diversity. Because large values of I or A do not necessarily lead to large values of N, although they do increase the spatial representativeness of $\mathrm{N}$, we assigned them a smaller importance (weight $=0.75$ ) with respect to $\mathrm{N}$. We assigned an even smaller importance (weight $=0.5$ ) to $\mathrm{S}$, which is simply the frequency or constancy with which studies containing quantitative tree community surveys are conducted in a given area. Our final rankings were insensitive to minor changes in the values of weights, but rankings calculated without weighting were somewhat different (not shown). Therefore, weighted rank was the more appropriate way to display how knowledge is distributed across AF regions, forest types, research institutions and conservation categories.

The growth of knowledge on AF structure was assessed by comparing the fits of two models that represented competing hypotheses that either this knowledge is growing continuously or is stabilizing over time. Using data from the past 50 years (1962-2013), we fitted a non-saturating function (power-law) and a saturating function (logistic) to three measures of knowledge: total number of studies, total individuals and total area sampled per year. Functions were fitted using non-linear least squares regression (Pinheiro and Bates 2000) and their performance was compared using Akaike's Information Criteria (AIC). Differences in AIC values that were higher than 2 were regarded as indicative of differences in function performance (Burnham and Anderson 2002). Analyses were performed using R (R Core Team 2014).

\section{Results}

\section{Surveys in space and time}

We retrieved a total of 2879 potential references that after filtering resulted in a final list of 1157 references on the AF that met our criteria; however we did not have access to the full text of 130 of these references (Table 1, Electronic supplementary material 2). The most 
Table 1 Number of studies about the Atlantic Forest found from each source and at each stage of the systematic review

a Only records not found in the other sources were included here

b Pre-selection performed after title and abstract inspection

c Removal of studies published using the same data or different censuses from the same sample

\begin{tabular}{lr}
\hline Source and stages of review & Studies \\
\hline Online scientific databases & 409 \\
Digital libraries of universities & 381 \\
Bibliographical search in the literature & 405 \\
Contact with local experts $^{\text {Google Scholar }}{ }^{\mathrm{a}}$ & 1335 \\
Total of potential studies retrieved & 236 \\
Studies selected for full text inspection $^{\mathrm{b}}$ & 2879 \\
Relevant studies after full text inspection $^{\mathrm{c}}$ & 2301 \\
Relevant studies with duplicated data $^{\mathrm{c}}$ & 1516 \\
Relevant studies not accessible $^{\text {Relevant studies fully accessible }}$ & 359 \\
Total of relevant Atlantic Forest studies & 130 \\
\hline
\end{tabular}

common vehicle of publication was local journals (44\%), but $37 \%$ of the studies were unpublished monographs and technical reports (Table S3). Approximately $56 \%$ of the studies were conducted by 18 universities located in southern and southeastern Brazil (Table S4). The 1027 studies that we had access to the full text contained a total of 2441 surveys comprising 2.24 million individuals and 1817 ha of sampled forest. Although these values seem large, this total sampled area represented only $0.01 \%$ of the remaining AF. Virtually none of the states or AF types reached proportions higher than $0.02 \%$ (Table 2).

The surveys were not well distributed in space (Fig. 1). States from southern and southeastern Brazil, which shelter $67 \%$ of the AF remnants, constituted $84 \%$ of the total sampled area. Some states had low sampled areas relative to their contributions to the remaining AF area, while others presented the opposite trend (Table 2). We found that 86 , 58 and $48 \%$ of the forest areas sampled in Alagoas, Santa Catarina, and Minas Gerais, respectively, resulted from state forest inventories (Tavares et al. 1971; Scolforo et al. 2008; Vibrans et al. 2013). The three largest AF types (evergreen, semi-deciduous, and Araucaria forests; $81 \%$ of the remaining AF) concentrated the same $81 \%$ of the total sampled area. However, semi-deciduous forests were clearly oversampled, while evergreen, open canopy (i.e., Brejos de Altitude) and deciduous forests remained undersampled (Table 3). We found no accurate estimates of the remnants of AF subtypes, such as cloud, swamp and Mussununga forests; however, judging from their total sampled areas (16.7, 9.6 and 1.7 ha, respectively), it seems that these subtypes are also underrepresented. Although one-third of the studies did not provide any information on the conservation statuses of the forests studied, we found that surveys within private lands had equal or greater contributions than those conducted within conservation units under strict protection (Table 4). If we assume that the many surveys without conservation statuses were conducted outside of strict protection units, then the largest input to the knowledge of AF structure comes from unprotected forests.

The number of studies that were conducted greatly increased after the 1980s. Important contributions before that decade were made by Veloso and Klein who published eight studies between 1945 and 1970, surveying more than 140,000 trees. We found evidence that the number of studies published is reaching an asymptote of $\sim 70$ studies being published per year (Fig. 2a), a result that remained unaltered if we considered only the number of studies after the 1980s. The same was not true for the total area or number of 
Table 2 Number of studies, surveys and total effort by region of the Atlantic Forest

\begin{tabular}{|c|c|c|c|c|c|c|c|}
\hline $\begin{array}{l}\text { State/ } \\
\text { country }\end{array}$ & $\begin{array}{l}\text { AF cover } \\
(\mathrm{ha})^{\mathrm{a}}\end{array}$ & $\begin{array}{l}\text { \# of } \\
\text { studies }\end{array}$ & $\begin{array}{l}\text { \# of } \\
\text { surveys }\end{array}$ & $\begin{array}{l}\text { Total } \\
\text { trees }(\mathrm{N})\end{array}$ & $\begin{array}{l}\text { Total } \\
\text { area (ha) }\end{array}$ & $\begin{array}{l}\% \text { of AF } \\
\text { sampled }^{\mathrm{b}}\end{array}$ & $\begin{array}{l}\text { Weigh. } \\
\text { rank }\end{array}$ \\
\hline MG & $2,864,487$ & 188 & 390 & 553,351 & 404.9 & 0.0141 & 1.3 \\
\hline SP & $2,378,900$ & 244 & 435 & 464,409 & 286.1 & 0.0120 & 1.6 \\
\hline $\mathrm{SC}$ & $2,216,131$ & 75 & 529 & 374,807 & 291.1 & 0.0131 & 2.1 \\
\hline PR & $2,310,110$ & 158 & 244 & 231,372 & 264.2 & 0.0114 & 2.9 \\
\hline RS & $1,090,999$ & 157 & 217 & 194,255 & 125.1 & 0.0115 & 3.6 \\
\hline RJ & 814,562 & 93 & 152 & 83,650 & 54.7 & 0.0066 & 4.9 \\
\hline BA & $2,040,697$ & 44 & 122 & 77,297 & 89.2 & 0.0044 & 5.2 \\
\hline ES & 482,714 & 32 & 69 & 77,079 & 85.8 & 0.0178 & 6.1 \\
\hline PE & 201,825 & 62 & 77 & 49,328 & 38.5 & 0.0191 & 6.5 \\
\hline $\mathrm{AL}$ & 143,695 & 12 & 21 & 21,505 & 74.5 & 0.0518 & 8.3 \\
\hline GO & 29,976 & 17 & 22 & 20,966 & 22.8 & 0.0761 & 8.7 \\
\hline MS & 708,579 & 17 & 24 & 18,999 & 14.3 & 0.0020 & 9.3 \\
\hline PAR & $1,152,332$ & 14 & 33 & 12,804 & 15.4 & 0.0013 & 9.6 \\
\hline PB & 54,087 & 13 & 18 & 15,293 & 6.1 & 0.0113 & 10.5 \\
\hline ARG & $918,795^{\mathrm{c}}$ & 12 & 15 & 11,591 & 25.1 & 0.0027 & 10.9 \\
\hline CE & 64,249 & 5 & 11 & 14,838 & 6.0 & 0.0093 & 12.1 \\
\hline PI & 917,289 & 3 & 32 & 9186 & 3.6 & 0.0004 & 12.4 \\
\hline SE & 72,524 & 6 & 9 & 8016 & 3.8 & 0.0052 & 13.3 \\
\hline RN & 16,094 & 6 & 6 & 5253 & 5.0 & 0.0312 & 13.6 \\
\hline
\end{tabular}

See Methods for the definition of the weighted rank of each AF type

For Goiás state there was probably an overestimation due to the inclusion of deciduous forests in this study that were not included and mapped by SOS Mata Atlântica/INPE (2014)

${ }^{a}$ Remaining AF cover in ha (SOS Mata Atlântica/INPE 2014)

b Proportion of the remaining forest area sampled

c Primary, secondary and gallery forests (Plací and Di Bitetti 2006)

trees sampled per year (Fig. 2b, c), suggesting that the number of studies is not increasing but their average sampling effort is. The differences between power-law and logistic fits remained similar when analyses were performed without the top two ranked states (Minas Gerais and São Paulo—results not shown). The effort outliers in 2008 and/or 2013 were largely related to the publication of the forest inventories of Minas Gerais and Santa Catarina, respectively.

\section{Survey methods}

The majority of surveys had low sampled areas (median $=0.4$; mean \pm $\mathrm{SD}=0.79 \pm 1.8 \mathrm{ha}$ ), with only 25 and $1 \%$ of studies having $\geq 1$ and $\geq 10$ ha, respectively (Fig. 3a). The surveys with the largest sampled areas (26 ha of Araucaria forest containing 18,427 trees, Cubas 2011; 24 ha of Tabuleiro forest with 12,285 trees, Jesus and Rolim 2005) were not the ones with the largest number of individuals sampled $(40,030$ trees in 10.24 ha of Restinga forest, Oliveira et al. 2014) due to their different cutoff criteria. Half of the surveys with area $\geq 10$ ha were conducted in Araucaria forests; however, none of these surveys had a cutoff criterion that was less restrictive than diameter 
Table 3 Number of studies, surveys and total effort by Atlantic Forest types

\begin{tabular}{|c|c|c|c|c|c|c|c|}
\hline AF type & $\begin{array}{l}\text { AF cover } \\
(\mathrm{ha})^{\mathrm{a}}\end{array}$ & $\begin{array}{l}\text { \# of } \\
\text { studies }\end{array}$ & $\begin{array}{l}\text { \# of } \\
\text { surveys }\end{array}$ & $\begin{array}{l}\text { Total } \\
\text { trees }(\mathrm{N})\end{array}$ & $\begin{array}{l}\text { Total } \\
\text { area (ha) }\end{array}$ & $\begin{array}{l}\% \text { of AF type } \\
\text { sampled }^{\mathrm{b}}\end{array}$ & $\begin{array}{l}\text { Weigh. } \\
\text { rank }\end{array}$ \\
\hline Semi-deciduous forest & $5,487,589$ & 440 & 854 & 826,573 & 648.6 & 0.0142 & 0.8 \\
\hline Evergreen forest & $9,640,098$ & 312 & 830 & 700,432 & 531.5 & 0.0066 & 1.5 \\
\hline Araucaria forest & $4,013,988$ & 135 & 311 & 288,027 & 371.9 & 0.0111 & 2.3 \\
\hline $\begin{array}{l}\text { Pioneer forest- } \\
\text { Restinga }\end{array}$ & 407,974 & 82 & 139 & 171,513 & 63.6 & 0.0187 & 3.2 \\
\hline Deciduous forest & $2,159,999$ & 35 & 63 & 91,651 & 92.2 & 0.0051 & 4.0 \\
\hline Pioneer forest—Alluvial & 616,198 & 79 & 110 & 79,252 & 46.0 & 0.0090 & 4.2 \\
\hline Ecotones & 975,504 & 38 & 41 & 63,640 & 44.7 & 0.0055 & 5.1 \\
\hline $\begin{array}{l}\text { Open canopy forests } \\
\text { (Brejos de altitude })\end{array}$ & 260,329 & 18 & 26 & 24,086 & 9.6 & 0.0044 & 6.0 \\
\hline Unclassified $^{\mathrm{d}}$ & - & 61 & - & - & - & - & - \\
\hline
\end{tabular}

The $\%$ of AF type represents the percentage of remaining Atlantic Forest area surveyed in each forest type. See Methods for the definition of the weighted rank of each AF type

${ }^{a}$ Remaining AF cover in ha per forest type (Cruz and Vicens 2007)

${ }^{\mathrm{b}}$ Proportion of the remaining forest area sampled

${ }^{\mathrm{c}}$ Here, we classified all Brejos de Altitude from northeastern Brazil as open canopy forests, although these forest types are sometimes referred to as montane semideciduous forests or ecotones between semi-deciduous and savanna formations

${ }^{\mathrm{d}}$ Unclassified studies were those that we did not have access to the full text of and that did not provided forest types in their abstracts

at breast height $(\mathrm{dbh}) \geq 10 \mathrm{~cm}$. Indeed, surveys conducted using larger dbh cutoff criteria tended to present larger sample areas and to sample less individuals (Fig. S1). Trends for number of individuals per survey were quite similar (median $=463$; mean $\pm \mathrm{SD}=980 \pm 1919$ individuals), with only 30 and $0.7 \%$ of studies having $\geq 1000$ and $\geq 10,000$ individuals, respectively (Fig. 3b).

The surveys were conducted using a great variety of methods that when combined rarely resulted in comparable sampling protocols. We found 126 different combinations of sampling methods, arrangements of samples and size cutoff criteria. However, there was a tendency in the surveys of using square or rectangular plots (85\% of the surveys), $\mathrm{dbh} \geq 4.8-5.0 \mathrm{~cm} \mathrm{(48 \% )}$ or $\mathrm{dbh} \geq 9.8-10.0 \mathrm{~cm} \mathrm{(25 \% )}$ as inclusion criteria (Table S5), as well as the systematic allocation of samples $(71 \%)$. The contribution from surveys using $\mathrm{dbh} \geq 10.0 \mathrm{~cm}$ was mainly due to the surveys of the Santa Catarina state forest inventory. Other methods, such as PCQ and transects, were much less common. We found evidence that the contributions of different methods changed over the last 25 years, with an increasing number of studies using plots and dbh as their sampling method and inclusion criteria, respectively (Fig. 4).

\section{Discussion}

We found that our current knowledge on the structure of the AF is based on only $0.01 \%$ of the 18.5 million ha of forest that are remaining. For specific states and AF types, this knowledge is even smaller. The implications of such scarce knowledge on the conservation of AF biodiversity are unknown, but they are of great concern. Furthermore, although we 
Table 4 Descriptive results of the Atlantic Forest studies with respect to the conservation categories and protection statuses of the surveyed forests

\begin{tabular}{lrrlrc}
\hline Category of protection & $\begin{array}{c}\text { \# of } \\
\text { studies }\end{array}$ & \multicolumn{1}{c}{$\begin{array}{l}\text { \# of } \\
\text { surveys }\end{array}$} & $\begin{array}{l}\text { Total } \\
\text { trees (N) }\end{array}$ & $\begin{array}{l}\text { Total } \\
\text { area (ha) }\end{array}$ & Rank \\
\hline Private land & 372 & 663 & 679,876 & 409.5 & 0.9 \\
Strict protection conservation unit & 373 & 520 & 530,711 & 399.8 & 1.2 \\
Biological and ecologic station & 51 & 64 & 97,054 & 62.7 & \\
National, state and municipal parks & 234 & 338 & 335,419 & 234.2 & \\
Biological, ecological and forest reserve & 84 & 112 & 96,408 & 99.4 & \\
Biological and ecological refuges & 4 & 6 & 1829 & 3.4 & \\
Sustainable use conservation unit & 118 & 214 & 295,907 & 264.4 & 2.3 \\
Environment protection area (APA) & 45 & 92 & 64,353 & 50.1 & \\
Relevant ecological and touristic interest ${ }^{\mathrm{a}}$ & 3 & 3 & 2648 & 1.0 & \\
Experimental stations & 13 & 17 & 16,413 & 23.8 & \\
National and state forests & 25 & 39 & 136,483 & 153.2 & \\
Natural heritage private reserve (RPPN) & 32 & 63 & 76,010 & 36.3 & \\
Research and academic institutions & 76 & 95 & 116,357 & 84.2 & 3 \\
University campus & 67 & 85 & 101,039 & 78.0 & \\
Botanical garden & 9 & 10 & 15,318 & 6.2 & \\
Other public lands & 16 & 25 & 16,425 & 16.4 & 3.8 \\
Military areas & 11 & 12 & 9319 & 5.7 & 4.5 \\
Indian territory & 2 & 3 & 2870 & 1.7 & 5.3 \\
Studies not accessible & 101 & 109 & 20,648 & 23.5 & - \\
No information available & 132 & 776 & $552,708.4$ & 597.5 & - \\
\hline
\end{tabular}

See Methods section in the main text for the definition of the weighted rank

a Areas of relevant ecological (ARIE) and touristic interests (AEIT)

b Squares, urban forests and other types of public lands
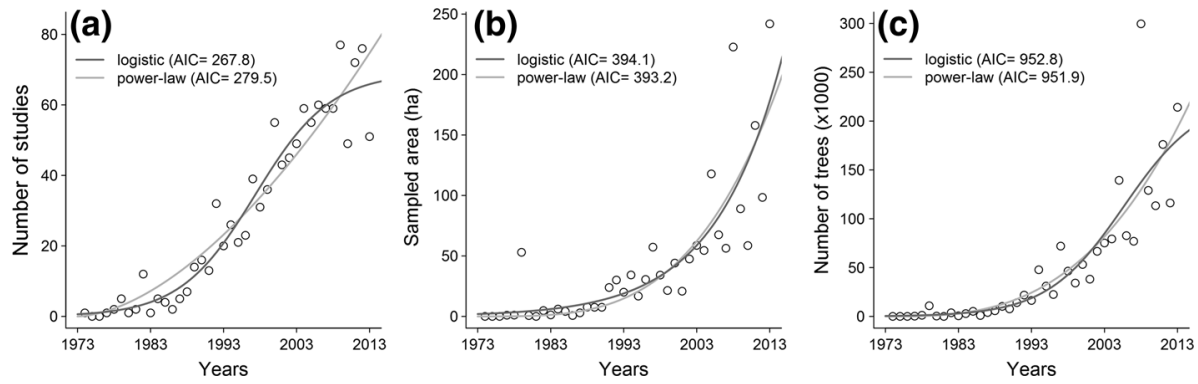

Fig. 2 The growth of knowledge about the Atlantic Forest over time with respect to a the number of studies, $\mathbf{b}$ the total area and $\mathbf{c}$ the number of trees sampled per year. Although the analysis was performed to include the past 50 years (1962-2013), the figure presents only the last 40 years for clarity. AIC Akaike's Information Criteria of logistic and power-law functions 

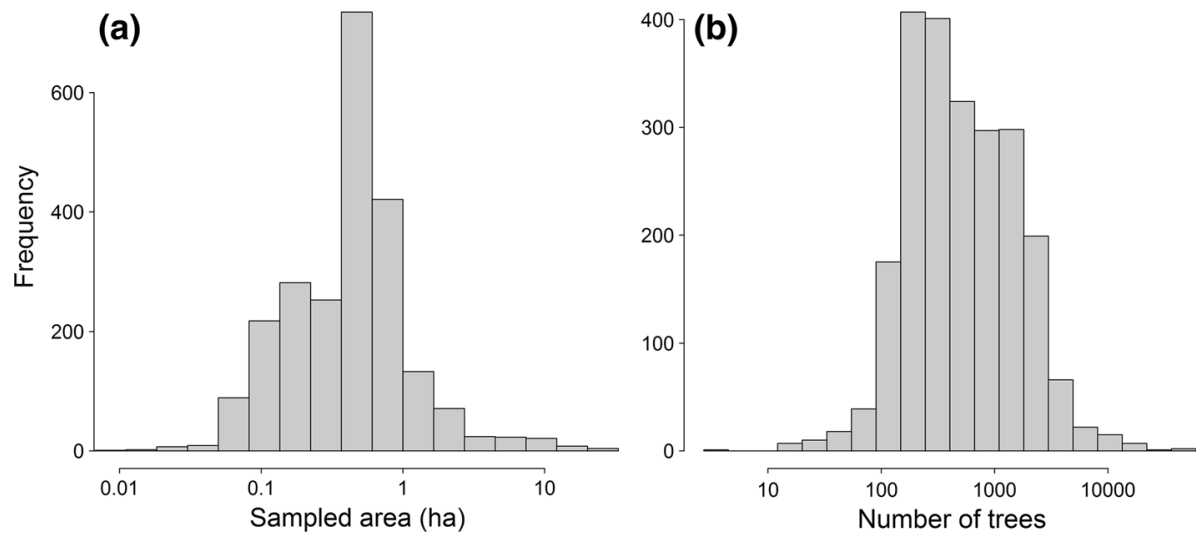

Fig. 3 Frequency distribution of a the sampled area and $\mathbf{b}$ total number of trees of each Atlantic Forest survey considered in this study. Note that both $x$-axes are in log-scale
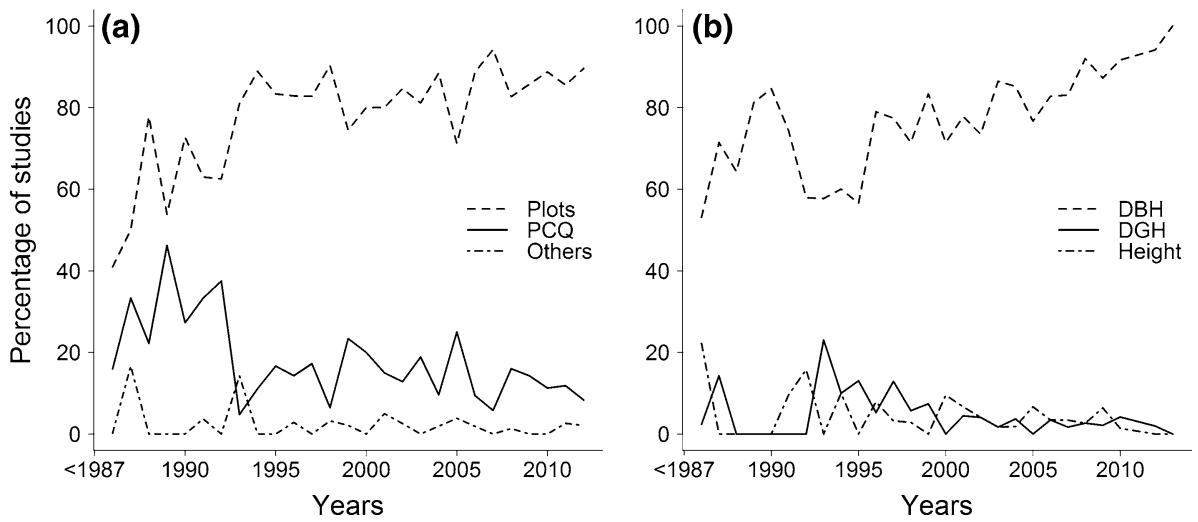

Fig. 4 Evolution of methods through time regarding a sampling method and $\mathbf{b}$ inclusion criteria of Atlantic Forest surveys. $P C Q$ point-centered quarter method; $D B H$ diameter at breast height; $D G H$ diameter at ground height

found that sampled area is increasing each year, if we keep the rate of increase that was found for the last four decades we will need 110 years to sample $1 \%$ (i.e., 185,000 ha) of the remaining AF. The threatened AF, which continues to be deforested today, will not withstand this length of time, especially because existing conservation units protect less than $10 \%$ of its remnants (Ribeiro et al. 2009). Rates of deforestation of the AF hotspot, which should be close to zero, are in fact four orders of magnitude larger than rates of sampling, meaning that most of the AF will disappear before the structure and diversity of its forests are properly described. We did not find similar estimates for other Neotropical domains; however, with the exception of the Amazon, where quantitative surveys are available in comparable or higher amounts (ter Steege et al. 2013, http://www.ctfs.si.edu), other domains are probably much less studied. Because the studies that were retrieved varied greatly in the type, quantity and quality of available information, not all of them may be useful for performing a synthesis of AF structure and diversity. On the other hand, 
the amount of AF knowledge reported here does not include natural regeneration studies or studies on non-tree species. However, because the majority of quantitative surveys of the AF are focused on adult-stages of tree communities (Hargreaves 2008, electronic supplementary material 1), knowledge available on other life stages and forms is presumably more incipient.

The obvious strategy to overcome such scarce knowledge is to stimulate surveys with large sampling efforts ( $>10 \mathrm{ha})$ that cover large spatial scales. We found that state inventories were of great importance, and the ongoing inventories in Rio de Janeiro, Paraná and Rio Grande do Sul states (http://ifn.florestal.gov.br) will increase our knowledge of AF structure. However, it is crucial that future surveys use methods comparable to the existing surveys and have the highest taxonomic resolution possible so that we can combine as much of such information as possible in planning conservation and management programs, as well as in answering scientific questions on the structure and diversity of the AF throughout its domain (Giehl and Budke 2011). Although specific studies require specific protocols, a minimum protocol should be observed. Here, we found that surveys using multiple 10-20 $\times 10-25 \mathrm{~m}$ plots to sample trees with $\mathrm{dbh} \geq 5 \mathrm{~cm}$ were the most common sampling protocols. Similar tendencies were found by Caiafa and Martins (2007) and Hargreaves (2008). Therefore, the decision of the Brazilian government to conduct state inventories using $\mathrm{dbh} \geq 10 \mathrm{~cm}$ may be suitable for the Amazon forests (cf. ter Steege et al. 2013), but it goes against the pattern of research that has been conducted on the AF. This will make it hard (if not impossible) to merge the knowledge of $\sim 480$ ha of AF that were sampled using this minimum protocol (Table S5), because the cutoff criteria greatly influences survey results (Caiafa and Martins 2007). Studies with more inclusive cutoffs (e.g., dbh $\geq 1 \mathrm{~cm}$ ) are also useful given that they present results for trees $\mathrm{dbh} \geq 5 \mathrm{~cm}$ as well. A minimum effort of 1 ha is also preferable because metrics of species richness, diversity and rarity are traditionally given in hectares, and they may depend on complicated statistical inference to be extrapolated from smaller samples sizes (Colwell et al. 2012).

Our results have shown that some regions and forest types of the AF are less studied than others. Futures efforts should survey evergreen and deciduous forests, especially in the Brazilian states of Bahia and Mato Grosso do Sul and in Paraguay and Argentina. Although the number of studies found on the AF in Paraguay and Argentina may indeed reflect a small effort, we must consider a possible "Brazilian bias" in the search for grey literature that may contain a considerable number of studies in these two countries that were not accessible to us. A closer look at the distribution of the surveys also reveals potential gaps of knowledge in western São Paulo and Paraná, northern Rio Grande do Sul and northeastern Minas Gerais (Figs. S2, S3). However, a detailed analysis is still needed to determine if these gaps are due to a lack of forest remnants in the first place and not to a lack of surveys. In addition, our results suggest that rare AF subtypes, such as cloud, swamp, Caxetal and Mussununga forests, are still underrepresented within the AF. In addition to their rarity, cloud and Mussununga forests may also shelter considerable levels of plant endemisms (Thomas et al. 1998; Meireles and Shepherd 2015). Therefore, making wise decisions to conserve the AF will depend not only on obtaining more quality information but also on more homogeneous coverage of these rarer or more threatened $\mathrm{AF}$ formations.

Acknowledgments Special thanks to Ary T. Oliveira-Filho for providing the digital version of the TreeAtlan list of references and to Bruno T. Walter for providing information on several other studies. We are also grateful to Ricardo R. Rodrigues, João L.F. Batista, Jefferson L. Polizel and André Amorim for 
providing their published and unpublished datasets in digital form. This study was supported by the grant 2013/08722-5, São Paulo Research Foundation (FAPESP) provided to the first author. Carolina Bello and Luiz F.S. Magnago were supported by the grant 2013/22492-2 (FAPESP) and by Floresta-Escola project, respectively.

\section{References}

Burnham KP, Anderson DR (2002) Model selection and multimodel inference: a practical informationtheoretic approach, 2nd edn. Springer, New York

Caiafa AN, Martins FR (2007) Taxonomic identification, sampling methods, and minimum size of the tree sampled: implications and perspectives for studies in the Brazilian atlantic rainforest. Funct Ecosyst Communities 1:95-104

Cain SA, Castro GMO, Pires JM, Silva NT (1956) Application of some phytosociological techniques to Brazilian rain forest. Am J Bot 43:911-941

Campos JCC, Heinsdijk D (1970) A floresta do Morro do Diabo. Silv São Paulo 7:43-58

Colwell RK et al (2012) Models and estimators linking individual-based and sample-based rarefaction, extrapolation, and comparison of assemblages. J Plant Ecol 5:3-21

Corona P, Chirici G, McRoberts RE, Winter S, Barbati A (2011) Contribution of large-scale forest inventories to biodiversity assessment and monitoring. For Ecol Manag 262:2061-2069

Cruz CBM, Vicens RS (2007) Levantamento da cobertura vegetal nativa do bioma Mata Atlântica IESB/ UFRJ/UFF, PROBIO/Ministério do Meio Ambiente, Rio de Janeiro. Technical Report. http://www. mma.gov.br/biomas/mata-atlantica/mapa-de-cobertura-vegetal. Accessed 25 Nov 2014

Cubas R (2011) Florística, estrutura e dinâmica em uma floresta ombrófila mista no norte do estado de Santa Catarina. Dissertation, Universidade Estadual do Centro-Oeste

Davis DE (1945) The annual cycle of plants, mosquitoes, birds, and mammals in two Brazilian forests. Ecol Monogr 15:243-295

Freitas WK, Magalhães LMS (2012) Métodos e parâmetros para estudo da vegetação com ênfase no estrato arbóreo. Floresta Ambient 19:520-540

Giehl ELH, Budke JC (2011) Aplicação do método científico em estudos fitossociológicos no Brasil: em busca de um paradigma. In: Felfili JM, Eisenlohr PV, Melo MMRF, Andrade, LA (orgs) Fitossociologia no Brasil: métodos e estudos de caso. Editora UFV, Viçosa, pp 1-21

Goerck JM (1997) Patterns of rarity in the birds of the Atlantic Forest of Brazil. Conserv Biol 11:112-118

Hargreaves P (2008) Phytosociology in Brazil. J Plant Sci Biotechnol 2:12-20

Jesus RM, Rolim SG (2005) Fitossociologia da Mata Atlântica de Tabuleiro. Bol Téc SIF 19:1-149

Joly CA, Assis MA, Bernacci LC, Tamashiro JY, Campos MCRD, Gomes JAMA, Belinello R (2012) Floristic and phytosociology in permanent plots of the Atlantic Rainforest along an altitudinal gradient in southeastern Brazil. Biota Neotrop 12:125-145

Kim KC, Byrne LB (2006) Biodiversity loss and the taxonomic bottleneck: emerging biodiversity science. Ecol Res 21:794-810

Magnago LFS, Edwards DP, Edwards FA, Magrach A, Martins SV, Laurance WF (2014) Functional attributes change but functional richness is unchanged after fragmentation of Brazilian Atlantic forests. J Ecol 102:475-485

Martins FR (1979) O método de quadrantes e a fitossociologia de uma floresta residual do interior do estado de São Paulo. Thesis, Universidade de São Paulo

Martins FR (1989) Fitossociologia de florestas do Brasil: um histórico bibliográfico. Pesquisas 40:103-164

MEA-Millennium Ecosystem Assessment (2005) Ecosystems and human well-being: biodiversity synthesis. World Resources Institute, Washington, DC

Meireles LD, Shepherd GJ (2015) Structure and floristic similarities of upper montane forests in Serra Fina mountain range, southeastern Brazil. Acta Bot Bras 29:58-72

Morris WF, Doak DF (2002) Quantitative conservation biology: theory and practice of population viability analysis. Sinauer Associates, Sunderland

Myers N, Mittermeier RA, Mittermeier CG, Fonseca GAB, Kent J (2000) Biodiversity hotspots for conservation priorities. Nature 403:853-858

Oliveira AA, Vicentini A, Chave J, Castanho CT, Davies SJ, Martini AMZ, Lima RAF, Rodrigues RR, Iribar A, Souza VC (2014) Habitat specialization and phylogenetic structure of tree species in a coastal Brazilian white-sand forest. J Plant Ecol 7:134-144 
Oliveira-Filho AT, Fontes MAL (2000) Patterns of floristic differentiation among Atlantic Forests in southeastern Brazil and the influence of climate. Biotropica 32:793-810

Pinheiro J, Bates D (2000) Mixed-effects models in S and S-PLUS. Springer, New York

Plací G, Di Bitetti M (2006) Situación ambiental en la ecorregión del bosque Atlántico del alto Paraná (Selva Paranaense). In: Martinez OU, Acerbi M, Corcuera J (eds) La situación ambiental argentina 2005. Fundación Vida Silvestre Argentina, Buenos Aires, pp 197-210

Pullin AS, Stewart GB (2006) Guidelines for systematic review in conservation and environmental management. Conserv Biol 20:1647-1656

R Core Team (2014) R: a language and environment for statistical computing. R Foundation for Statistical Computing, Vienna. http://www.R-project.org/. Accessed 30 July 2014

Ribeiro MC, Metzger JP, Martensen AC, Ponzoni FJ, Hirota MM (2009) The Brazilian Atlantic Forest: how much is left, and how is the remaining forest distributed? Implications for conservation. Biol Conserv 142:1141-1153

Rode R, Figueiredo-Filho A, Machado SDA, Galvão F (2011) Floristic groups and discriminant species in stands with Araucaria angustifolia and a mixed ombrophilous forest. Rev Árvore 35:319-327

Rodrigues RR (2005) Parcelas Permanentes em 40 ha de florestas do Estado de São Paulo: uma experiência interdisciplinar. ESALQ/USP, Piracicaba. http://www.lerf.esalq.usp.br/parrel2005.php. Accessed 20 May 2013

Scolforo JR, Mello JM, Silva CPC (2008) Inventário Florestal de Minas Gerais. UFLA, Lavras. http://www. inventarioflorestal.mg.gov.br Accessed 10 Nov 2013

Scudeller VV, Martins FR (2003) FITOGEO-Um banco de dados aplicado à fitogeografia. Acta Amaz 33:9-21

Soberón J, Peterson AT (2004) Biodiversity informatics: managing and applying primary biodiversity data. Philos Trans R Soc Lond B 359:689-698

SOS Mata Atlântica, INPE (2014) Atlas dos remanescentes florestais da Mata Atlântica: período 2012-2013. Technical Report. http://www.sosmatatlantica.org.br. Accessed 25 Nov 2014

Tavares S, Paiva FAF, Carvalho GH, Tavares EJS (1971) Inventário florestal em Alagoas: contribuição para determinação do potencial madeireiro dos municípios de São Miguel dos Campos, Chão de Pilar, Colônia de Leopoldina e União dos Palmares. Bol Recur Nat SUDENE 9:123-231

ter Steege H (1998) The use of forest inventory data for a National Protected Area Strategy in Guyana. Biodivers Conserv 7:1457-1483

ter Steege $\mathrm{H}$ et al (2013) Hyperdominance in the Amazonian tree flora. Science 342:1243092

Thiollay JM (2002) Bird diversity and selection of protected areas in a large neotropical forest tract. Biodivers Conserv 11:1377-1395

Thomas WW, Carvalho AMV, Amorim AM, Garrison J, Arbeláez AL (1998) Plant endemism in two forests in southern Bahia, Brazil. Biodivers Conserv 7:311-322

Veloso HP (1945) As comunidades e estações botânicas de Teresópolis, Estado do Rio de Janeiro (com um ensaio de chave dendrológica). Bol Mus Nac 3:1-95

Veloso HP (1946) A vegetação do município de Ilhéus, Estado da Bahia, I-Estudo sinecológico das áreas de pesquisas sobre a febre amarela silvestre realizado pelo SEPFA. Mem Inst Oswaldo Cruz 44:13-103

Veloso HP (1992) Manual técnico da vegetação brasileira. IBGE, Rio de Janeiro

Veloso HP, Klein RM (1957) As comunidades e associações vegetais da mata pluvial do sul do Brasil I. As comunidades do município de Brusque, Estado de Santa Catarina. Sellowia 8:81-235

Veloso HP, Klein RM (1968) As comunidades e associações vegetais da mata pluvial do sul do Brasil VI. Agrupamentos arbóreos dos contra-fortes da Serra Geral situados ao sul da costa catarinense e ao norte da costa sul-riograndense. Sellowia 20:127-180

Vibrans AC, Sevgnani L, Gasper AL, Lingner DV (2013) Inventário florístico florestal de Santa Catarina (IFFSC). Edifurb, Blumenau. http://www.iff.sc.gov.br. Accessed 10 Nov 2013 